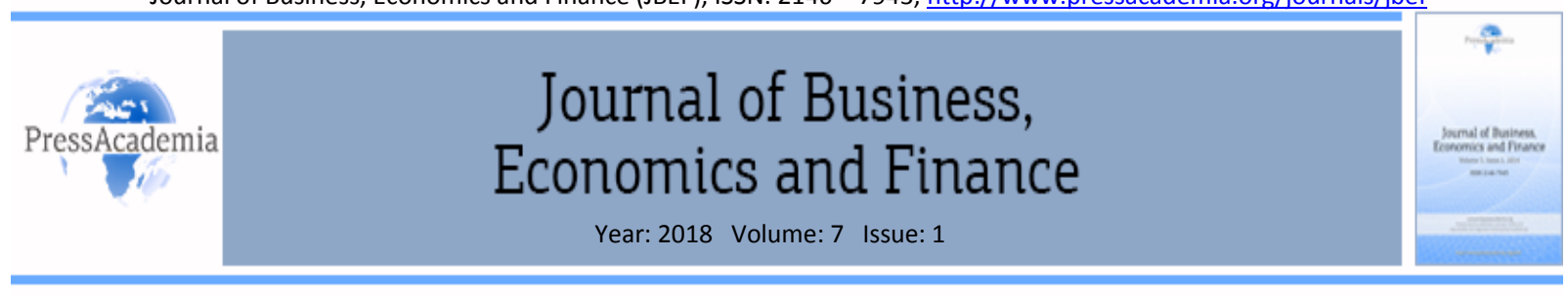

\title{
NONLINEAR EQUILIBRIUM RELATIONSHIP BETWEEN INFLATION AND EMPLOYMENT: EVIDENCE FROM CÔTE D'IVOIRE
}

\author{
DOI: 10.17261/Pressacademia.2018.796 \\ JBEF- V.7-ISS.1-2018(7)-p.76-82
}

Coffie Francis José N'Guessan

Felix Houphouet-Boigny University, CIRES , 08 BP 1295 Abidjan 08, Côte d'Ivoire. coffiejose@cires-ci.com, ORCID: 0000-0002-4484-6484

To cite this document

N'Guessan, C.F.J., (2018). Nonlinear equilibrium relationship between inflation and employment: evidence from Côte d'Ivoire. Journal of Business, Economics and Finance (JBEF), V.7(1), p.76-82

Permemant link to this document: http://doi.org/10.17261/Pressacademia.2018.796

Copyright: Published by PressAcademia and limited licenced re-use rights only.

\begin{abstract}
Purpose- The main objective of this paper is to test the existence of a stable long-run relationship between price level and employment for an African country.

Methodology- This paper employs two types of co-integration and error correction methodologies: the Engel-Granger cointegration model which assumes symmetric adjustment toward equilibrium and a Threshold co-integration approach that considers asymmetric adjustment toward equilibrium. Before making cointegration analysis we apply unit root test to check for the stationnarity of the series.

Findings- We found evidence of a stable long-run relationship between price level and employment in Côte d'Ivoire and a positive relationship between the two variables. However, the adjustment towards the equilibrium is asymmetric since positive shocks are absorbed more rapidly than negative ones. Moreover, there was no causality between the two variables in the short run.

Conclusion- The results indicate that in Côte d'Ivoire, inflation stability may be incomptaible with employment maximization. So to reduce unemployment rate, it is necessary to accept a certain level of inflation rate.
\end{abstract}

Keywords: Phillips curve, inflation, employment, symmetric co-integration, threshold co-integration JEL Codes: C32, C51, E31

\section{INTRODUCTION}

Since the seminal paper of Phillips (1958), many studies have been undertaken to investigate the relationship between unemployment and inflation. Phillips found a negative relationship between the rate of change in nominal wages and the rate of unemployment. However, this relationship was popularized by Samuelson and Solow (1960) in regards to inflation rate and unemployment. The Phillips relationship has led in considering a trade-off between unemployment and inflation.

This relationship has been used to forecast inflation rate. The Phillips Curve has been studied by many authors for developed countries. Due to lack of data, there are not enough studies for African countries. Yet, investigating this relationship for African countries where employment is majorly informal may gi ve additional information for a better understanding of the link between the market of goods and services and that of labor. We are interested in Côte d'Ivoire; the economic leader of the West African Economic Monetary Union (WAEMU) countries. In this country, the WAEMU criteria convergence among which the inflation rate which should be lower than $3 \%$ is a main objective of the Government. But, for the Government, youth unemployment reduction is also a very important goal. So it is necessary to inform whether employment is to be lost if we want to stabilize or reduce inflation?

The contribution of this paper is in twofold. First, we document the studies about the relationship between inflation and labor market indicators in African countries by studying the relationship between inflation proxied by the Consumer Price Index and employment. Then, we try to evaluate the stability of the relationship by taking into account the possibility of frictions relating to inflation and employment. Also, we compare a Threshold co-integration model and a Symmetric co- 
integration one. Our results indicate that the Symmetric approach fails to detect co-integration relationship, while the Threshold technique shows a stable equilibrium relationship between Consumer Price Index and employment.

The rest of the paper is as follows: Section 2 gives a brief literature review of the relationship between labor market indicators and inflation, Section 3 describes the methodology. Section 4 presents the data, Section 5 discusses the results, and Section 6 concludes the paper.

\section{LITERATURE REVIEW}

The studies about the relationship between unemployment (or employment) and inflation gave mixed conclusions. Some validated the Phillips's relationship while others disputed it.

Islam et al. (2011) using data from North Cyprus over the period 1978-2007 conclude that there is a stable relationship between unemployment and inflation in the long-run. Also, there is a trade-off between unemployment and inflation in the short and long-run. Tang and Lean (2007) investigate the Phillips curve in Malaysia for the period 1971-2004. They used an ARDL model and found a trade-off between inflation and unemployment both in the short and long-run.

Hasanov et al. (2010) for Turkey, over the period 1980-2008, found that the Phillips relationship is unstable over time. Ormerod et al. (2013) also showed that the Phillips curve is unstable over time. Thus, many papers have discussed the linearity of this relationship. Gordon (1997) and Aguiar and Martins (2005) found linearity in the Phillips curve. Eliason (2001) studied the Phillips curve for three countries: Australia, Sweden, and the United States. This was done using a smooth transition regression model. She suggested non-linearity in the Phillips curve for Australia and Sweden, but linearity for the United States. Kumar and Orrenius (2015) showed evidence of non-linearity in the Phillips Curve. Hasanov et al. (2010) used a time varying smooth transition regression model. Also, they found that the Phillips relationship is nonlinear. Ormerod et al. (2013) also showed non linearity. It was also corroborated by Barnes and Olivei (2003) and Peach et al. (2011). Barnes and Olivei (2013) found an unemployment threshold interval within which unemployment has no influence on inflation, and outside which there is a significant relationship between unemployment and inflation. Peach et al. (2011) opines that when the unemployment rate is higher than $1.56 \%$, it points to the natural rate of unemployment. The inverse relationship between the unemployment rate and the inflation rate was confirmed.

Many studies about this relationship have been undertaken in developed countries. For African countries, they are not enough. Among the rare studies in Africa, we can cite that of Umaru and Zubairu (2012) and Taiwo and Folorunso (2013) for Nigeria; Vermeulen (2017), Hodge (2002) and Burger and Marinkov (2006) for South Africa. Umaru and Zubairu, over the period 1977-2009, found no relationship between inflation and unemployment in the short- run, but a relationship in the long-run. For the same country over the period 1970-2010, Taiwo and Folorunso found a negative relationship between inflation rate and unemployment rate in the short run and a positive relationship in the long run. Burger and Marinkov (2006) in South Africa showed evidence of a negative relationship between inflation and employment in the long run, and there was no significant relationship in the short run. Hodge (2002), over the period 1983-1998, found no relationship between inflation and employment or unemployment. Vermeulen (2017) found a positive short-run relationship between inflation and employment growth, while there was a significant negative relationship in the long-run.

These mixed results may be due to the model used. Umaru and Zubairu (2012) used Johansen Co-integration analysis to test for a stable long-run relationship, while Taiwo and Folorunso's approach was an ARDL model. Vermeulen used EngelGranger and ARDL approaches. These models are symmetric co-integration methods. The use of a symmetric co-integration approach means that making the assumption of no asymmetries in the long run adjustment mechanism. If this assumption does not hold in the reality, it can give a misleading conclusion. It is thus necessary to use a more general approach which can take into account the problem of asymmetries.

\section{DATA AND METHODOLOGY}

The data used in the study are the consumer price index, a measure of the price level and number of people employed over the period 1960-2014. This time span is due to data availability. The data on consumer price index are taken from the World Bank data base (World Development Indicator 2016) and the employment level was obtained from the Penn world table 9.0 (Feenstra et al., 2015). Table 1 gives the descriptive statistics of these variables in their logarithm form. 
Table 1: Descriptive Statistics

\begin{tabular}{|c|c|c|c|c|}
\hline Data & Definition & Source & Mean & $\begin{array}{l}\text { Standard } \\
\text { Deviation }\end{array}$ \\
\hline $\ln P t$ & $\begin{array}{l}\text { Logarithm of Consumer } \\
\text { Price Index }\end{array}$ & $\begin{array}{l}\text { World Development Indicator } 2016 \\
\text { (World Bank) }\end{array}$ & 3.396 & 1.034 \\
\hline $\ln L t$ & $\begin{array}{l}\text { Logarithm of the number of } \\
\text { persons employed }\end{array}$ & $\begin{array}{l}\text { Penn World Table } 9.0 \text { (Feenstra et } \\
\text { al., 2015) }\end{array}$ & 1.286 & 0.555 \\
\hline $\mathrm{N}$ & 55 & & & \\
\hline
\end{tabular}

The Phillips relationship is a link between an indicator of inflation and that of aggregate demand which can be output gap and unemployment rate or employment growth. Following Tang and Lean (2007), we choose log of Consumer Price Index as proxy for inflation. Also, due to lack of long time series on unemployment rate, we use the level of employment as an aggregate demand indicator.

Our purpose is to estimate the following relationship:

$\ln P_{t}=\alpha+\beta \ln L_{t}+\gamma T+\mu_{t}$

where $\ln _{t}$ is the natural logarithm of Consumer Price Index (CPI) and $I n L_{t}$ is the logarithm of the level of employment, $T$ is a time trend, $\alpha, \beta$ and $\gamma$ are the parameters to estimate, and $\mu_{t}$ is the error term.

Furthermore, we hypothesize that an increase in labor demand induces an increase in the wage level that is transmitted by firms to the prices of goods.

The first step of our estimation methodology is to use the traditional Engel and Granger (1987) procedure by first estimating via Ordinary Least Squares the long-run equilibrium equation (1). The second step involves using the residuals in (1) to estimate $\rho$ in the following equation:

$\Delta \hat{\mu}_{t}=\rho \hat{\mu}_{t-1}+\varepsilon_{t}$

Where $\varepsilon_{t}$ is a white-noise disturbance. The co-integration implies that $\mu_{\mathrm{t}}$ is stationary.

However, this standard co-integration test is unstipulated if the adjustment process is asymmetric. Therefore, Enders and Granger (1998) and Enders and Siklos (2001) suggested the Threshold Autoregressive (TAR) model and the Momentum Threshold Autoregressive model (MTAR). We opt for the MTAR model because we are interested in how the disequilibrium is resorbed when the inflation rate (the growth of price) deviates from its long-run term. So, the second step involves using the residuals in (1) to estimate the following Momentum Threshold Autoregressive model (MTAR):

$$
\Delta \hat{\mu}_{t}=I_{t} \rho_{1} \hat{\mu}_{t-1}+\left(1-I_{t}\right) \rho_{2} \hat{\mu}_{t-1}+\varepsilon_{t}
$$

Where It is the indicator function such that:

$$
I_{t}=\left\{\begin{array}{l}
1 \text { if } \Delta \hat{\mu}_{t-1} \geq \tau \\
0 \text { if } \Delta \hat{\mu}_{t-1}<\tau
\end{array}\right.
$$

Where $\mathcal{\tau}$ is the threshold parameter.

If the errors $\mu_{t}$ in equation 3 are serially correlated, it is possible to use an augmented threshold model for the residuals. In this circumstance, equation 3 is replaced by:

$$
\Delta \hat{\mu}_{t}=I_{t} \rho_{1} \hat{\mu}_{t-1}+\left(1-I_{t}\right) \rho_{2} \hat{\mu}_{t-1}+\sum_{i=1}^{p} \gamma_{i} \Delta \hat{u}_{t-i}+\varepsilon_{t}
$$

Some studies may use a threshold value of zero. However, since there is no reason to expect the threshold to be zero, it is necessary to estimate the value of $\tau$. This is done by applying the procedure proposed by Chan (1993) which is to search over the potential threshold values such as to find the one which minimizes the sum of squared errors from the fitted model. Specifically, the estimated residuals from 1 are sorted in ascending order. This was done with the largest and 
smallest $15 \%$ of the values discarded. For each of the remaining values, equation (3) is estimated, and the threshold value is selected as the one which minimizes the sum of squared residuals.

The adjustment is modeled by $\rho_{1} \hat{\mu}_{t-1}$ if $\Delta \hat{\mu}_{t-1}$ is above the threshold, and by $\rho_{2} \hat{\mu}_{t-1}$ if $\Delta \hat{\mu}_{t-1}$ is below the threshold. Petrucelli and Wooldford (1984) show that the necessary and sufficient conditions for stationarity of $\mu$ t is: $-2<\rho_{1}, \rho_{2}<0$ and $(1+\rho 1) \cdot\left(1+\rho_{2}\right)<1$.

To check for asymmetric co-integration, we use the Enders and Siklos (2001) test called the $\Phi$ statistics. The $\Phi$ statistic is testing a joint procedure with the null hypothesis of no co-integration $\mathrm{H}_{0}: \rho_{1}=\rho_{2}=0$. If the null hypothesis of no cointegration is rejected, we test for the null hypothesis of symmetric adjustment, $\mathrm{HO}: \rho_{1}=\rho_{2}$, by a standard F-statistic.

The error correction models are estimated as follows:

$\Delta \ln P_{t}=\alpha+\sum_{i=1}^{p} \beta_{i} \Delta \ln P_{t-i}+\sum_{j=1}^{q} \delta_{j} \Delta \ln L_{t-j}+\rho_{11} I_{t} \mu_{t-1}+\rho_{12}\left(1-I_{t}\right) \mu_{t-1}+v_{t}$

$\Delta \ln L_{t}=\lambda+\sum_{i=1}^{p} \Gamma_{i} \Delta \ln P_{t-i}+\sum_{j=1}^{q} \Omega_{j} \Delta \ln L_{t-j}+\rho_{21} I_{t} \mu_{t-1}+\rho_{22}\left(1-I_{t}\right) \mu_{t-1}+\omega_{t}$

\section{FINDINGS AND DISCUSSIONS}

Since it is important to check for the stochastic properties of the series before implementing co-integration analysis, we apply the Elliot-Rosenberg-Stock (1996) unit-root test which modifies the Dickey-Fuller test by using generalized least squares. This test has good performances with small samples. The results are shown in Table 2. We can see that the level of employment and the price level are not stationary, but I (1). Thus, this conclusion allows us to now investigate the cointegration analysis.

Table 2: Dickey-Fuller GLS Unit-Root Test

\begin{tabular}{|c|c|c|c|c|c|c|c|c|}
\hline & \multicolumn{2}{|c|}{ InPt } & \multicolumn{2}{|c|}{$\Delta \operatorname{lnPt}$} & \multicolumn{2}{|c|}{ InLt } & \multicolumn{2}{|c|}{$\Delta \operatorname{lnLt}$} \\
\hline & $\begin{array}{c}\text { No } \\
\text { Trend }\end{array}$ & Trend & $\begin{array}{c}\text { No } \\
\text { Trend }\end{array}$ & Trend & $\begin{array}{c}\text { No } \\
\text { Trend }\end{array}$ & Trend & $\begin{array}{c}\text { No } \\
\text { Trend }\end{array}$ & Trend \\
\hline$\tau_{D F-G L S}$ & -0.314 & -1.203 & -3.708 & -2.903 & -0.076 & -1.764 & -1.562 & -3.227 \\
\hline$P$ & 3 & 1 & 0 & 9 & 7 & 2 & 2 & 5 \\
\hline Critical values & & & & & & & & \\
\hline $1 \%$ & -2.611 & -3.759 & -2.609 & -3.770 & -2.615 & -3.762 & -2.611 & -3.770 \\
\hline $5 \%$ & -1.947 & -3.180 & -1.947 & -3.190 & -1.948 & -3.184 & -1.947 & -3.190 \\
\hline $10 \%$ & -1.613 & -2.881 & -1.613 & -2.890 & -1.612 & -2.884 & -1.613 & -2.890 \\
\hline
\end{tabular}

Note: Lag length obtained by $\mathrm{Ng}$-perron $\mathrm{t}$-sequential method. $\Delta$ stands for the first difference of the variable

Table 3 shows the estimation of the coefficients of the long-run relationship. The long run employment coefficient is positive and significant at $1 \%$. A growth in employment leads to an increase in the price level determined by the Consumer Price Index. The long run coefficient is 3.336 . When employment increases by $1 \%$, the price level grows by $3.336 \%$.

Table 3 also shows the results of the co-integrations analyses. To eliminate serial correlation in the residuals, we used the sequential t-test procedure which consists of selecting the lagged error that is significant. We also refer to the Ljung-Box autocorrelation statistics. These statistics indicate that the augmented residual lag of order one is to be used. The cointegration results show that the Engel-Granger test fails to reject the hypothesis of no co-integration between the price level and employment. This is because the mac-kinnon p-value is higher than $10 \%$. So, following the symmetric cointegration approach, there is no stable relationship between inflation and employment in the long-run. Consequently, we turn to the M-TAR model to investigate whether there is an asymmetry in the equilibrium adjustment mechanism. The estimated consistent threshold value following the Chan's method is found to be 0.01949 . Implying that:

$$
I_{t}= \begin{cases}1 & \text { if } \Delta \hat{\mu}_{t-1} \geq 0.01949 \\ 0 & \text { if } \Delta \hat{\mu}_{t-1}<0.01949\end{cases}
$$

Since the Enders and Siklos table does not provide critical values for a long run equation with a trend, the critical values of the $\Phi$ statistic have been generated for a long run equation with a trend and a sample size of 55 . The simulation was performed 30,000 times using $N(0,1)$ serially uncorrelated pseudo random-numbers for thresholds values equal to 0.000 and 0.01949 respectively. 
The co-integration analysis is thus implemented with these critical values. The results indicate the M-TAR model with a threshold value of zero, fails to reject the null hypothesis of no co-integration relationship between CPI and employment. The $\Phi$ statistic is 6,747 and lower than the critical values. However, with the consistent threshold value of 0.01949 , the $\Phi$ statistic is 7.861 which is higher than the critical value at $10 \%$ significance level. In addition, the standard F-statistic is also significant at $10 \%$. With the consistent Threshold value, the null hypothesis of no co-integration is thus rejected in favor of an asymmetric co-integration relationship between the price level and the level of employment. In addition, we can notice that the estimate of $\rho_{1}$ is -0.291 and that of $\rho_{2}$ is -0.096 . This indicates faster adjustment when the disequilibrium is due to increase in consumer price or decrease in employment (so that $\Delta \hat{\mu}_{t-1} \geq 0.01949$ ).

Table 3: Symmetric and Asymmetric Co-integration Results

\begin{tabular}{|c|c|c|c|}
\hline \multirow{2}{*}{ Variables } & \multirow{2}{*}{ Engel-Granger } & \multicolumn{2}{|c|}{ M-TAR } \\
\hline & & $\boldsymbol{\tau}=\mathbf{0}$ & $\tau=0.01949$ \\
\hline$I_{t} \mu_{t-1}$ & $\begin{array}{l}-0.175 \\
(-3.390)\end{array}$ & $\begin{array}{c}-0.241 \\
(-3.390)\end{array}$ & $\begin{array}{l}-0.291 \\
(-3.687)\end{array}$ \\
\hline$\left(1-I_{t}\right) \mu_{t-1}$ & - & $\begin{array}{l}-0.104 \\
(-1.413)\end{array}$ & $\begin{array}{l}-0.096 \\
(-1.45)\end{array}$ \\
\hline$\Delta u_{t-1}$ & $\begin{array}{c}0.412 \\
(3.480)^{* * *}\end{array}$ & $\begin{array}{c}0.410 \\
(3.490)^{* * *}\end{array}$ & $\begin{array}{c}0.410 \\
(3.554)^{* * *}\end{array}$ \\
\hline Ljung-Box Q Statistics & Prob. & Prob. & Prob. \\
\hline$Q(1)$ & 0.781 & 0.733 & 0.733 \\
\hline$Q(4)$ & 0.803 & 0.946 & 0.946 \\
\hline$Q(8)$ & 0.912 & 0.878 & 0.878 \\
\hline Mc Kinnon P-value & 0.158 & - & - \\
\hline$F\left(\rho_{1}=\rho_{2}=0\right)$ & - & 6.740 & $7.861^{*}$ \\
\hline \multicolumn{4}{|l|}{ Generated $\Phi$ Critical values } \\
\hline \multicolumn{2}{|l|}{$1 \%$} & 10.983 & 10.940 \\
\hline \multicolumn{2}{|l|}{$5 \%$} & 8.212 & 8.183 \\
\hline \multicolumn{2}{|l|}{$10 \%$} & 6.980 & 6.983 \\
\hline Standard F test : $F\left(\rho_{1}=\rho_{2}\right)$ & - & 1.806 & $3.635^{*}$ \\
\hline Long - run equation $: \ln P_{t}=$ & $=\begin{array}{c}0.559 \\
(5.108) * * *\end{array}$ & $\begin{array}{l}+3.336 \operatorname{lnL} L_{t}-0 . \\
(10.269) * * *(-4.6\end{array}$ & \\
\hline
\end{tabular}

N.B : t-statistics in parenthesis ${ }^{* * *}$,indicates significant at $1 \% ; *$,indicates significant at $10 \%$.

The error correction model developed thereafter is presented below. The results confirm the co-integration relationship. In the price level equation, the positive discrepancy error correction term is -0.302 and that of negative discrepancy is -0.099 . However the positive error correction term is significant at 1 percent level, while that of negative is not significant. This indicates that the price level adjusts to deviations from long-run equilibrium only when $\Delta \hat{\mu}_{t-1} \geq 0.01949$. Moreover, in the employment equation, all the error correction terms are insignificant. So, employment is weakly exogenous with respect to the long-run equilibrium. Besides, employment does not granger-cause the price level in the short run and vice versa. But the price level and the employment level are determined by their past values. So there exists a long-run causality between employment and Consumer Price index but no short-run causality.

$$
\begin{aligned}
& \Delta \ln \mathrm{P}_{\mathrm{t}}=-0.015+0.436 \Delta \operatorname{lnp}_{\mathrm{t}-1}+1.336 \Delta \operatorname{lnL}_{\mathrm{t}-1}-0.302 \mathrm{I}_{\mathrm{t}} \hat{\mathrm{u}}_{\mathrm{t}-1}-0.099\left(1-\mathrm{I}_{\mathrm{t}}\right) \hat{\mathrm{u}}_{\mathrm{t}-1} \\
& \begin{array}{lllll}
(-0.585) & (3.843) * * * & (1.650) \quad(-3.903) * * * \quad(-1.545)
\end{array} \\
& \Delta \operatorname{lnL}_{\mathrm{t}}=0.004+0.011 \Delta \operatorname{lnp}_{\mathrm{t}-1}+0.860 \Delta \operatorname{lnL}_{\mathrm{t}-1}-0.004 I_{\mathrm{t}} \hat{\mathrm{u}}_{\mathrm{t}-1} \quad-0.0007\left(1-\mathrm{I}_{\mathrm{t}}\right) \hat{\mathrm{u}}_{\mathrm{t}-1} \\
& (1.710) * \quad(1.107) \quad(12.167) * * * \quad(-0.586) \quad(-0.126)
\end{aligned}
$$

Note: Lag length selected by AIC criterion, t-statistics in parenthesis. ***, indicates coefficient significant at $1 \%$.

These findings contradict the resuts of Vermeulen (2017), Hodge (2002) and Burger and Marinkov (2006). But support that of Umaru and Zubairu who found a long-run relationship between inflation and unemployment but no short-run relationship. 


\section{CONCLUSION}

The main objective of this paper was to test for the existence of a stable relationship between inflation as measured by Consumer Price Index and the level of employment. We found that with co-integration symmetric approach, the hypothesis of no stable relationship cannot be rejected. Conversely, with the asymmetric co-integration approach, this hypothesis is rejected. In conclusion, there exists a stable long-run relationship between inflation and employment in Côte d'Ivoire, and the relationship is positive. Employment growth induces increasing price level in the long-run. However, there is no causality between the two variables in the short run.

The results indicate that in Côte d'Ivoire, inflation stability may be incomptaible with employment maximization. So to reduce unemployment rate, it is necessary to accept a certain level of inflation rate. Our findings confirm the conclusions of Umaru and Zubairu (2012) but suggest that analysis on estimating the stability of the Phillips Curve should take into account asymmetries in the long-run adjustments mechanisms.

\section{REFERENCES}

Aguiar, A. and Martins, M.M.F. (2005). Testing the significance and the non-linearity of Phillips trade-off in the Euro area. Empirical Economics, 30(3), 665-691.

Barnes, M. R. and Olivei, G. P. (2003). Inside and Outside Bounds Threshold estimate of the Phillips Curve. New England Economic Review, 3-18.

Burger, P and Marinkov, M. (2006). The South African Phillips Curve: How applicable is the Gordon Model? . South African Journal of Economics, 74(2), 172-189.

Chan, K.S. (1993). Consistency and Limiting Distribution of the Least Squares Estimation of a Threshold Autoregressive Model. The Annals of Statistics, 21(1), 520-533.

Eliasson A-C. (2001). Is the short run Phillips Curve nonlinear? Empirical Evidence for Australia, Sweden and The United States. Sveriges Risksbank Working paper series, No.124

Elliot, B. Rothenberg, T. and Stock, J. (1996). Efficient tests of the unit root hypothesis. Econometrica, 64(8), 13-36.

Enders,W and Siklos, P.L. (2001). Co-integration and Threshold adjustment. Journal of Business and Economic Statistics, 19(2), 166-176.

Engel, R. F. and Granger C.W. (1987). Co-integration and Error correction: Representation, estimation and testing. Econometrica, $55(2), 251-276$

Feenstra, R.C., Inklaar, R., and Timmer, M.P. (2015). The Next Generation of the Penn World Table. American Economic Review, 105(10), 3150-3182.

Gordon, R. (1997). The time-varying NAIRU and its implications for Economic Policy. Journal of Economic Perspectives, .4(1), 11-32.

Hasanov M., Araç A., Telatar F. (2010). Nonlinearity and structural stability in the Phillips Curve: Evidence from Turkey. Economic Modeling, 27(5), 1103-1115.

Hodge, D.(2002). Inflation versus unemployment in South Africa: Is there a trade-off?. South African Journal of Economics, 70(3), $193-204$.

Islam F. Shahbaz M. and Shabbir M. (2011). Phillips Curve in a small open Economy: A time series exploration of North Cyprus. MPRA paper No.28397, Retrieve from: http://mpra.ub.uni-muenchen.de/2397/.

Ormerod, P., Rosewell, B. and Phelps, P. (2013). Inflation, Unemployment regimes and the instability of the Phillips curve. Applied Economics, 4(12), 1519-1531. DOI:10.1080/00036846.201.628299.

Peach, R. W., Rich, R. W., and Cororaton, A. (2011). How does slack influence inflation?. Current Issues in Economics and Finance, 17(3), .17.

Petrucelli, J. and Woodford, S. (1984). A Threshold AR(1) Model. Journal of Applied Probability, 21(2), 270-286.

Phillips, A.W. (1958). The relation between unemployment and the rate of change of money wage rates in the United Kingdom, $1861-1957$. Economica, 25(100), 283-299.

Samuelson, P. A. and Solow, R. M. (1960). Analytical Aspect of Anti-Inflation Policy. American Economic Review, 50(2), $177-194$.

Taiwo, V. O. and Folorunso, E. (2013). Does Phillips Relation Really Exist in Nigeria?Empirical Evidence. International Journal of Economics and Finance, 5(9), 123-133.

Tang C.F and Lean H.H. (2007). The stability of Phillips Curve in Malaysia. Monash University Business and Economics Discussion paper No.39. 
Kumar A. and Orrenius P. (2015). A Closer look at the Phillips Curve using state level data. Federal Reserve Bank of Dallas Research Department Working Paper No.1409

Umaru, A. and Zubairu A.B. (2012). An empirical Analysis of the Relationship between unemployment and Inflation in Nigeria from19772009. Economics and Finance Review, 1(2), 42-61.

Vermeulen J.C. (2017). Inflation and unemployment in South Africa: Is the Phillips Curve still dead?. Southern African Business Review 21(1), 20-54 